JBSED

3,1

50

Received 18 April 2021

Revised 1 August 2021 21 August 2021

Accepted 31 August 2021

\section{Supplier performance in the public healthcare: internal social capital, logistics capabilities and supply chain risk management capabilities as antecedents in a developing economy}

\author{
Benjamin Tukamuhabwa \\ Procurement and Logistics Management, Makerere University Business School, \\ Kampala, Uganda, and \\ Henry Mutebi and Daniel Isabirye \\ Makerere University Business School, Kampala, Uganda
}

\begin{abstract}
Purpose - The purpose of this paper is twofold. First, it intends to explore the link between internal social capital, logistics capabilities, supply chain risk management (SCRM) capabilities and supplier performance. Second, the mediating effect of logistics capabilities between internal social capital and SCRM capabilities, and that of SCRM capabilities between logistics capabilities and supplier performance are also examined.

Design/methodology/approach - A theoretical model developed from the extant literature was empirically validated through a cross-sectional survey of 122 respondents in 52 public healthcare facilities in Uganda. The data were analysed using partial least square structural equation modeling (PLS-SEM).

Findings - The study found that internal social capital and SCRM capabilities are significant predictors of supplier performance. Internal social capital is positively and significantly related to logistics capabilities, and logistics capabilities are positively and significantly related to SCRM capabilities. The authors also found nonsignificant relationships between internal social capital and SCRM capabilities, and between logistics capabilities and supplier performance. Furthermore, it was revealed that logistics capabilities play a partial mediating role in the relationship between internal social capital and SCRM capabilities, while SCRM capabilities fully mediate between logistics capabilities and supplier performance.

Originality/value - Further to providing empirical evidence of the antecedents of supplier performance in the public healthcare in a developing economy, which has been evidently scant, this study provides initial empirical evidence of the mediating role of logistics capabilities in the relationship between internal social capital and SCRM capabilities and that of SCRM capabilities in the relationship between logistics capabilities and supplier performance. This is important for understanding the mechanism through which supplier performance can be enhanced.
\end{abstract}

Keywords Supplier performance, Logistics capabilities, Internal social capital,

Supply chain risk management capabilities, Healthcare

Paper type Research paper

\footnotetext{
(C) Benjamin Tukamuhabwa, Henry Mutebi and Daniel Isabirye. Published in Journal of Business and Socio-economic Development. Published by Emerald Publishing Limited. This article is published under the Creative Commons Attribution (CC BY 4.0) licence. Anyone may reproduce, distribute, translate and create derivative works of this article (for both commercial and non-commercial purposes), subject to full attribution to the original publication and authors. The full terms of this licence may be seen at http:// creativecommons.org/licences/by/4.0/legalcode

The authors acknowledge the almighty God for their lives and the tireless work done by the editors and reviewers. This article was funded by the authors.
}

Journal of Business and Socioeconomic Development Vol. 3 No. 1 ,
pp. $50-68$

Emerald Publishing Limited e-ISSN: 2635-1692

p-ISSN: $2635-1374$

DOI 10.1108/JBSED-04-2021-0046 


\section{Introduction}

The growing interest in the public sector supplier performance (SP) has been amplified by the colossal global spend through public procurement. Furthermore, the COVID-19 pandemic has exposed the vulnerabilities and deficiencies in the global healthcare supply chain. And being in the upstream, it is logical that the performance of suppliers fundamentally determines the performance of the entire supply chain. It is particularly understood that the performance of suppliers is imperative for the performance and competitiveness of buying organisations (Zsidisin et al., 2015; Lee et al., 2018). Through the vision 2040, the government of Uganda earmarks good health as fundamental for achieving socio-economic transformation and sustainable development goals. However, like many other African countries, Uganda still faces an acute risk of inadequate healthcare, especially relating to deficient local treatment (Jahre et al., 2012). There has been a remarkable endeavour to enhance the availability of drugs in Ugandan public health facilities, but deficiencies in supplier performance (SP) have remained significantly evident including shortages of essential medicines, delayed deliveries, expired essential medicines, poor quality of the medicines, cost escalations, supply of wrong specifications and price variations (BMAU report, 2017).

Past studies have emphasised that even the best performing suppliers are potentially vulnerable to risk events, which potentially undermine their performance (Riley et al., 2016; Mwesiumo et al., 2021). The challenge of supplier related risks and associated fatal repercussions in the healthcare sector are not a new phenomenon for both developing and developed countries. In the Ugandan health sector, reports on risk assessment indicate the prevalence of risks related to frequent drug stock-outs and demand-supply mismatch, inadequate technology, human resources related risks, transport risks, storage infrastructure shortages, power shortages, delays in supplies, poor quality drugs and health equipment and counterfeit drugs (BMAU report, 2017). Such risks call for building supply chain risk management (SCRM) capabilities, which can be in the form of warning and recovery (Riley et al., 2016), or resilience and robustness (Kwak et al., 2018; Yang et al., 2021). From the extant literature, it is noticeable that to date, studies on the antecedents of SCRM capabilities are still scant (Ahmed and Huma, 2021).

According to the extant literature, SCRM capabilities and SP have been linked to the concepts of logistics capabilities and social capital (Mentzer et al., 2004; Polyviou et al., 2019; Gölgeci and Kuivalainen, 2020). Whereas internal social capital includes structural, relational and cognitive dimensions (Polyviou et al., 2019), logistics capabilities comprise demand management, supply management and information management capabilities (Gligor and Holcomb, 2012, 2014). Studies on the role of social capital on positive performance outcomes have provided mixed results. For example, Kim et al. (2017) argued that social capital facilitates supplier performance. And Polyviou et al. (2019) underscored the role of internal social capital on improving SCRM capability of resilience. However, Alghababsheh and Gallear (2020) noted that social capital can lead to direct performance improvements but also cause risks that are counterproductive to performance in buyer-supplier relationships. The recent empirical studies on the antecedents of SP have focused on issues such as organisational context and supplier management practices (Chuah et al., 2010), contractual issues (Kim et al., 2017; Vlachos, 2020), supplier development (Lee et al., 2018; Brix-Asala et al., 2021), supplier relations (Field and Meile, 2008), bilateral dependency and fairness perceptions (Bhardwaj and Ketokivi, 2021), supply market scanning, internal communication and supply chain integration (Zsidisin et al., 2015) and institutional investment (Cheung et al., 2020).

Generally, the literature indicates that most of the recent studies on the antecedents of SP have focused on manufacturing firms in the private sector. In this study, we use the resource-based view and dynamic capabilities theoretical perspectives to show that internal social capital and SCRM capabilities significantly influence supplier performance in the public healthcare sector. Furthermore, we demonstrate the mediating role of logistics
Supplier
performance in the public healthcare 
JBSED 3,1

capabilities between internal social capital and SCRM capabilities, thereby contributing to the limited empirical studies on the antecedents of SCRM capabilities. Moreover, we reveal the full mediating role of SCRM capabilities in the relationship between logistics capabilities and SP.

The rest of this paper progresses as follows. Section 2 presents the theoretical background, literature review and hypotheses development. Section 3 then describes the research methodology used. Section 4 presents data analysis followed by section 5 with the discussion. Section 6 presents the conclusion together with the implications for theory and practice.

\section{Theoretical background}

The resource-based view (RBV) suggests that a firm's sustainable competitive advantage originates from its internal resources, which are assumed to be rare, valuable, inimitable and non-substitutable (Kraaijenbrink et al., 2010). The dynamic capabilities perspective addresses the gap in RBV by explaining how firms can develop, deploy, protect, renew and reconfigure resources and competencies to adapt to changes in the dynamic business environment and in the end achieve sustainable competitive advantage (Teece et al., 1997). It is stressed that performance differences across firms are due to their differential capacities regarding integration, utilisation, renewal and reconfiguration of resources in response to changing environments (Teece et al., 1997). In the supply chain literature, authors (e.g. Kwak et al., 2018) have considered dynamic capabilities as important for SCRM capabilities and competitive advantage. Scholars such as Kwak et al. (2018) empirically confirmed that SCRM capabilities positively influence competitive advantage. Gligor and Holcomb (2014) stressed that when logistics capabilities are strategically designed, they can reflect the features espoused within the RBV and hence provide a sustainable competitive advantage. Furthermore, logistics capabilities have been described as complex and dynamic capabilities (Gligor and Holcomb, 2012; Wiengarten et al., 2014). Other researchers have investigated logistics capabilities and SCRM capabilities of resilience and robustness as dynamic capabilities arguing that they are inherently adaptable (Ponomarov and Holcomb, 2009; Brandon-Jones et al., 2014). According to Dyer and Singh (1998), firm resources may include organisational capabilities, routines and many other attributes of supply chain relationships. This therefore underpins internal social capital as an organisational resource that can facilitate SP and competitive advantage.

\subsection{Literature review and hypotheses development}

2.1.1 Supplier performance. Improving SP has become one of the critical issues to be considered by firms wishing to gain competitive advantage (Cai et al., 2010). SP focuses on the ability of the supplier to satisfy the needs of the ultimate customers (Zelbst et al., 2010). Ahimbisibwe et al. (2012) argue that many of the services provided by the suppliers in the public sector suffer from poor SP, which turns costly to consumers of public services. Poor SP can manifest in the form of late deliveries, delivery unreliability, order incompleteness, poor delivery speed, poor quality of goods or services, delivery failures, defective deliveries, high prices and failure to match specifications (Ntayi et al., 2010). Prahinski and Benton (2004) operationalised SP in terms of product quality, delivery, price, responsiveness and service support. And in the context of the Ugandan public sector, Ahimbisibwe et al. (2012) considered conformance to specifications, lead time, cost, user complaints, quality and flexibility as the dimensions of SP.

There are several prior empirical studies on the antecedents of SP focussing on different dimensions and contexts. For example, Chuah et al. (2010) focused on manufacturing firms in China, Malaysia, Singapore and the USA, Vlachos (2020) focused on manufacturing firms in France, Lee et al. (2018) on Chinese manufacturing firms, Field and Meile (2008) on financial 
services in the USA, Bhardwaj and Ketokivi (2021) on railroad industry in India and Ojha et al. (2019) on manufacturing firms in the USA. Other recent studies on the enhancers of supplier performance have focused on antecedents such as supplier development (Brix-Asala et al., 2021), supplier selection and management (Salam and Khan, 2018), power use and justice (Chen and Chen, 2019). Generally, it is observed that most of the existing studies on the antecedents of SP have focused on manufacturing firms in the private sector, leaving a gap in our understanding of supplier performance in the public sector.

2.1.2 Internal social capital and supplier performance. According to the literature, the most commonly highlighted dimensions of social capital include structural, relational and cognitive capital. Structural capital refers to the links among a network's actors and their patterns with facets including ties among them and network configuration in terms of size, density, connectivity and hierarchy (Nahapiet and Ghoshal, 1998). Relational capital describes the quality of interpersonal relationships, and how they develop and strengthen over time (Whipple et al., 2015). Cognitive social capital encompasses shared codes and language as well as shared narratives (Johnson et al., 2013). Internal cognitive capital can be reflected in the employees' tenure in an organisation (Polyviou et al., 2019). Internal social capital improves information exchange, knowledge creation and accumulation within a firm (Nahapiet and Ghoshal, 1998). According to Polyviou et al. (2019), internal relational capital includes relationship closeness, commitment and respect. Internal structural capital includes geographical proximity among decision makers, while cognitive capital concerns "the resources providing shared representations, interpretations, and systems of meaning" among a network's actors (Nahapiet and Ghoshal, 1998). It has been observed that many of the studies on supply network performance have explored the effects of only single or dual dimensions of social capital (Cousins et al., 2006; Johnson et al., 2013).

Gligor and Holcomb (2014) found that firms' relational competences such as coordination, communication and cooperation can help to improve relational and financial performance. Similarly, Zsidisin et al. (2015) established positive and significant relationships between a firm's internal communication climate, internal integration and supplier performance. Huang et al. (2014) argue that greater internal integration enhances the ability of the focal firm to implement more effective knowledge-sharing routines and governance mechanisms that offer direct benefits for the supplier. In the same line, Narasimhan et al. (2008) established that there is a positive relationship between relational norms and SP manifested in volume flexibility, cost reduction and schedule flexibility. Related to this, Ojha et al. (2019) found that social exchange investments in relationship stability and information quality are important for supplier flexibility performance. Furthermore, Kim et al. (2017) underscored the role of social capital in facilitating suppliers' innovation performance. However, some researchers have suggested that supplier performance can also enhance social capital. For example, Paparoidamis et al. (2019) stressed that better supplier performance in product quality and sales service quality is vital for building social capital (Paparoidamis et al., 2019). Furthermore, Alghababsheh and Gallear (2020) underlined that social capital can lead not only to direct performance improvements but also generate risks that can undermine performance in buyer-supplier relationships. Hence the following hypothesis is derived:

\section{H1. Internal social capital positively influences supplier performance}

2.1.3 Internal social capital and logistics capabilities. According to Morash et al. (1996), logistics capabilities can be described as attributes, abilities, organisational processes, knowledge and skills that allow a firm to achieve superior performance. Several authors have suggested different dimensions of logistics capabilities (Mentzer et al., 2004; Esper et al., 2007). For example, Gligor and Holcomb (2012) operationalised logistics capabilities in terms of demand management, supply management and information management capabilities. Supply management capabilities relate to the supply-side and are concerned with relationships 
JBSED 3,1

with suppliers while information management capabilities relate to the firm's ability to analyse, store and distribute both internal and external strategic and tactical information (Gligor and Holcomb, 2012).

Studies have revealed that social capital is important for building different components of logistics capabilities. For example, Scott et al. (2014) stressed that relational capital positively affects logistics innovation capability. Carlos (2011) argued that in order to build new dynamic capabilities, firms need to leverage their social capital that provides access to novel sources of information. Similarly, Gligor and Holcomb (2014) indicated that firms' relational capital in terms of coordination, communication and cooperation lead to integrated logistics capabilities. With regard to information management capabilities, Li et al. (2014) revealed that relational capital and cognitive capital have significant positive influences on information sharing, while structural capital has an indirect effect. Several other scholars have supported the role of internal social capital dimensions in facilitating information exchange management capabilities (Kemper et al., 2013; Polyviou et al., 2019). It has also been acknowledged that internal social capital in terms of extensive cross-functional integration in the buying firm facilitates supplier involvement in the buying firm's effective logistics planning (Zhao et al., 2011). This therefore leads to the hypothesis below:

H2. Internal social capital positively influences logistics capabilities

2.1.4 Internal social capital and SCRM capabilities. Effective SCRM requires development of appropriate SCRM capabilities. There are two main views regarding the dimensions of SCRM capabilities. The first emphasises warning and recovery capabilities (Riley et al., 2016). The second and most recent operationalisation of SCRM capabilities embraces robustness and resilience dimensions (Kwak et al., 2018; Yang et al., 2021). Supply chain resilience involves readiness for response to and recovery from supply chain disruptions (Kwak et al., 2018), whereas supply chain robustness involves resistance and avoidance of supply chain disruptions, and maintaining normal operations (Wieland and Wallenburg, 2013).

The role of social capital in supply chain success is well-acknowledged in the literature. For example, Gligor and Holcomb (2012) indicated that personal relationships between managers can enhance trust, communication, business understanding and continuity of supply chains. Similarly, Riley et al. (2016) argued that a firm's internal social capital in the form of internal integration positively affects its warning and recovery SCRM capabilities. Wieland and Wallenburg (2013) stipulated that relational competences of communication and cooperation are important for building supply chain robustness and resilience. Similarly, Johnson et al. (2013) established that the dimensions of social capital may play an influential role in facilitating the formative capabilities for resilience. Polyviou et al. (2019) also revealed that internal social capital acts as a resource that enhances supply chain resilience. Pinho (2011) added that relational capital provides access to novel sources of information necessary to build dynamic capabilities to cope with turbulent and unpredictable environment. Furthermore, Cui et al. (2020) confirmed that risk managers' social capital play important roles in building corporate risk management capabilities. Similarly, Gao et al. (2013) observed that cognitive capital is the most important social capital facet for building risk management capabilities compared to structural and relational capital. Finally, although many scholars support the positive effect of social capital on SCRM capabilities, some have argued that social capital can be counterproductive to SCRM by creating more risks (Alghababsheh and Gallear, 2020). The following hypothesis is therefore advanced:

H3. Internal social capital positively influences SCRM capabilities

2.1.5 Logistics capabilities and supplier performance. According to Gligor and Holcomb (2012), logistics capabilities enable a firm to effectively and efficiently perform logistics activities leading to enhanced logistics performance. Rai et al. (2012) argued that the efficiency of 
logistics capabilities management is important in the coordination of suppliers and can directly influence the entire supply chain responsiveness (Gligor and Holcomb, 2012). According to Joong-Kun et al. (2008), logistics capabilities can make major contributions toward the achievement of superior performance and sustained competitive advantage. Chuah et al. (2010) add that supplier management capability enhances supplier performance. Relatedly, Fugate et al. (2010) argued that logistics capabilities play an important role in ensuring better performance of suppliers. Several other scholars support the positive role of supply management capabilities on SP improvements (Day et al., 2015; Salam and Khan, 2018). In addition, Brix-Asala et al. (2021) recently stressed that logistics integrative capabilities built during supplier development facilitates supplier performance. This leads to the hypothesis below:

\section{H4. Logistics capabilities positively influence supplier performance}

2.1.6 Logistics capabilities and SCRM capabilities. Logistics capabilities have been linked to effective SCRM. For example, scholars (Gligor and Holcomb, 2012, 2014) underscored the importance of logistics capabilities in effective response to market volatility, supply chain uncertainties and risk. Wang et al. (2018) indicated that logistics capabilities can help in mitigating supply chain uncertainty and risk. Similarly, Ponomarov and Holcomb (2009) stressed that firms possessing appropriate demand management, supply management and information management capabilities are able to create and maintain their supply chain resilience. This also concurs with Brandon-Jones et al. (2014)'s findings that information sharing increases supply chain resilience and robustness. In the same line, Mandal et al. (2016) found that integrated logistics capabilities positively influence resilience capabilities. Furthermore, Brix-Asala et al. (2021) revealed that logistical integration capabilities are important for managing supply chain risks related to non-transparent sourcing, poor transportation and quality deficiencies. Selvaraj and Wesley (2020) also emphasised that supply management and information management capabilities are important for SCRM. This therefore leads to the hypothesis below:

\section{H5. Logistics capabilities positively influence SCRM capabilities}

2.1.7 SCRM capabilities and supplier performance. Supply chain uncertainties and risks negatively affect SP as they disrupt the normal supply chain operations (Rodrigues et al., 2008). Supply chain risks can affect delivery schedule attainment, competitive performance and customer satisfaction (Zhao et al., 2013). Wagner and Bode (2008) found support for the negative associations between supply and demand risks and supply network performance. In addition, Weiland and Wallenburg (2013) indicated that supply chain robustness enhances customer value. Similarly, Zhang and Wang (2011) found a positive impact of supply chain robustness on supply network performance. Furthermore, Mandal et al. (2016) found that supply chain resilience positively influences supply chain performance. The study by Riley et al. (2016) revealed that managers can leverage their warning and recovery SCRM capabilities to enhance performance. The foregoing discussion indicates that many scholars support the positive influence of SCRM capabilities on supplier performance. However, some other scholars (Mwesiumo et al., 2021) stress that supplier performance weakens the effect of perceived supply risk on collaborative risk management. Hence, the hypothesis below is stated:

H6. SCRM capabilities positively influence supplier performance

2.1.8 Internal social capital, logistics capabilities and SCRM capabilities. Gligor and Holcomb (2014) indicated that firms' relational components of coordination, communication and cooperation lead to integrated logistics capabilities, which then lead to improved relational and financial performance. Scholars have provided support for the positive influence of social capital on logistics capabilities (Scott et al., 2014; Gligor and Holcomb, 2014). For example, 
JBSED 3,1

Polyviou et al. (2019) support the role of internal social capital dimensions in facilitating information exchange management capabilities. Improved logistics capabilities have also been linked to effective SCRM capabilities (Gligor and Holcomb, 2014; Wang et al., 2018; BrixAsala et al., 2021). However, Alghababsheh and Gallear (2020) reveals that social capital can lead to information exchange capability but also generate risks that pose threat to SCRM. Hence, the following hypothesis is stated:

H7. Logistics capabilities mediate between internal social capital and SCRM capabilities

2.1.9 Logistics capabilities, SCRM capabilities and supplier performance. According to Pinho (2011), information management capabilities help in building new dynamic capabilities that facilitate adaptability to the turbulent and unpredictable environment, which in turn positively influences performance. Tukamuhabwa et al. (2015) established that supply and demand management capabilities can enable supply chains to develop resilience capabilities, which help in improving performance in the form of cycle times, delivery competence and customer service. Scholars (Brandon-Jones et al., 2014) suggested that information management capability can help to increase visibility and create supply chain resilience and robustness. Furthermore, Brix-Asala et al. (2021) revealed that logistical integration capabilities are important for managing supply chain risks, which then leads to better supplier performance. This discussion leads to the following hypothesis:

H8. SCRM capabilities mediate between logistics capabilities and supplier performance

\section{Methodology}

\subsection{Design, population and sample}

We adopted a positivist epistemological position following a deductive cross-sectional approach to test for pre-specified research hypotheses. We studied health facilities from eastern Uganda, with 122 valid responses from 52 public healthcare facilities. The unit of analysis was a health facility, and that of inquiry included health facility managers, stores assistants and purchasing coordinators considered knowledgeable about supply chain related functions.

\subsection{Measurement of variables}

The questionnaire responses were anchored on a five-point Likert scale ranging from " 1 = Strongly Disagree (SD) to $5=$ Strongly Agree (SA)". The measures for all study variables were adapted from previously validated scales. For logistics capabilities, we used supply management capabilities and information management capabilities (Gligor and Holcomb, 2014). Internal social capital; structural capital, relational capital and cognitive capital (Polyviou et al., 2019), SCRM capabilities; robustness and resilience (Kwak et al., 2018; Yang et al., 2021), while SP; lead time, matching specifications, reduced user complaints, quality and flexibility (Ahimbisibwe et al., 2012).

\subsection{Measurement validation}

First, we assessed the suitability of data based on sample size adequacy with the KeiserMeyer-Olkin (KMO) and Bartlett tests. The KMO values for all of the variables yielded a cutoff well above 0.7 , which is considered acceptable, while the Bartlett's test of sphericity in all scales reached statistical significance. Later, we used confirmatory composite analyses (CCA) to test measurement quality of each study variable measurement scale (Hair et al., 2020). Study variables were modelled as a high order reflective-reflective measurement model (see Figure 1). We evaluated each CCA measurement model item loading > 0.708; reliability $>0.50$, Cronbach's alpha and composite reliability $>0.70$, average variance 


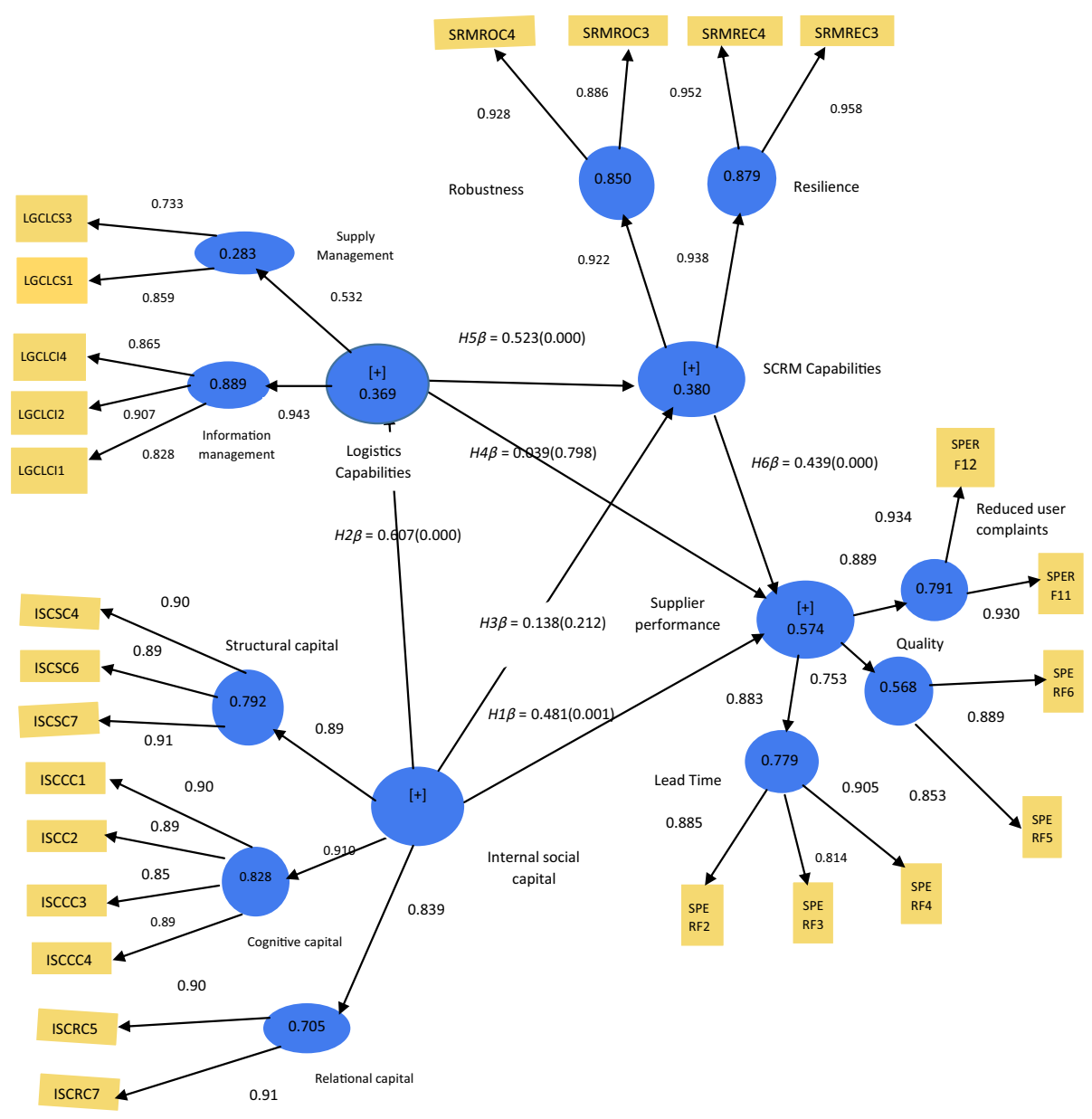

\section{Supplier performance in the public healthcare}

Figure 1. PLS-SEM model for supplier performance

extracted (AVE) $>0.50$ (Hair et al., 2020). The results in Table 1 show that all the conditions were met, indicating that the measurement items measure what they are intended to measure and since also the values of Cronbach alpha and composite coefficients for the study variables are above 0.7 threshold, the data were reliable. Discriminant validity was assessed using heterotrait-monotrait ratio of correlations (HTMT) (Henseler et al., 2015). From Table 2, we find that the values are below the minimum correlation ratio of 0.85 as recommended by Henseler et al. (2015), which shows that the independent variables are distinct from each other in predicting supplier performance.

\subsection{Common methods variance}

We adopted both procedural and post-analysis statistical remedies as recommended by Podsakoff et al. (2003) to control for common method variance. Procedural remedies included adapting of previously validated measurement scales for the study variables to the study context, keeping questions short and precise, avoidance of double-barrelled questions and limiting the use of negatively worded items. In addition, we ensured respondents' anonymity 
JBSED

3,1

58

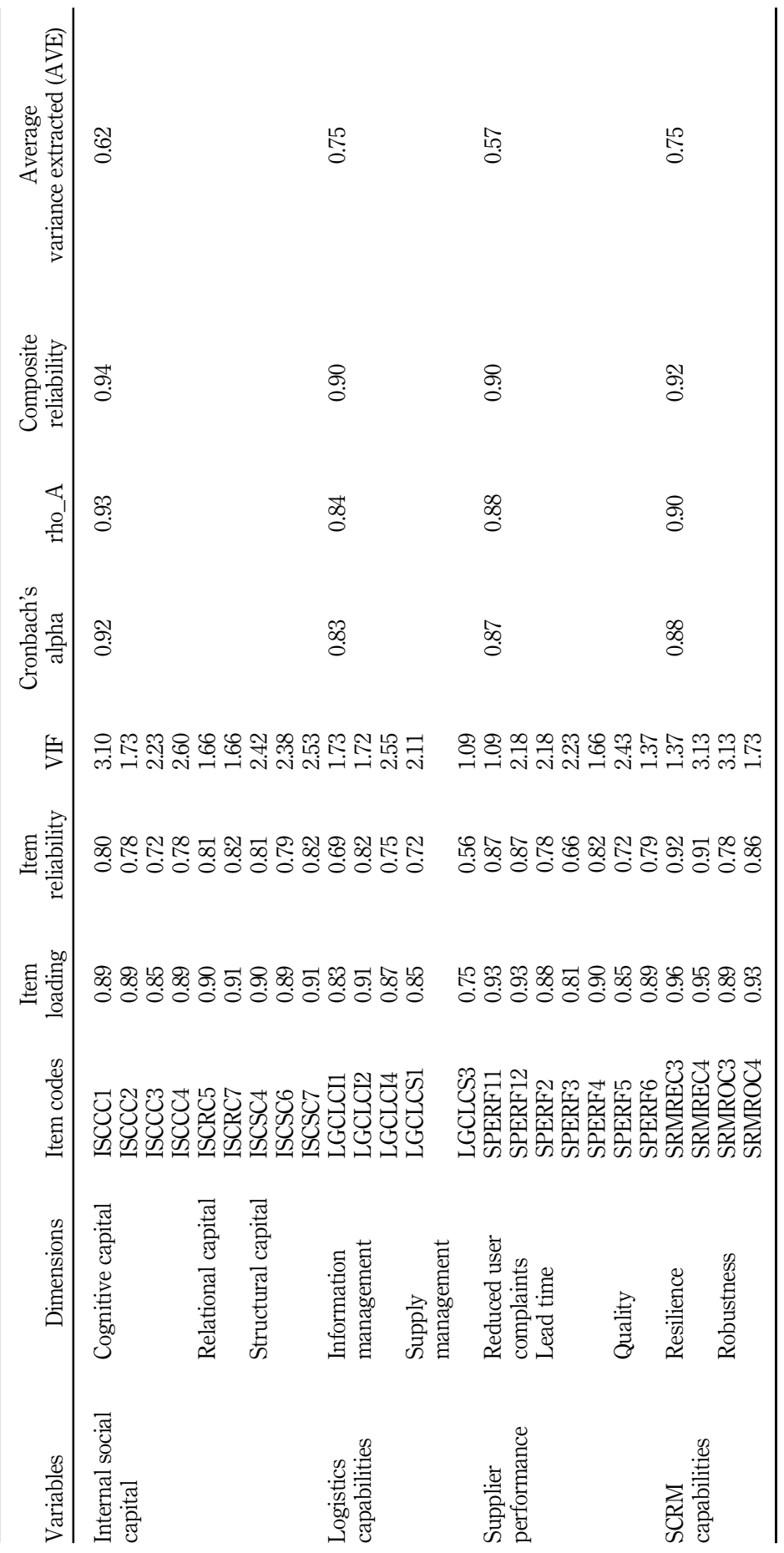

Table 1.

Reliability and convergent validity 


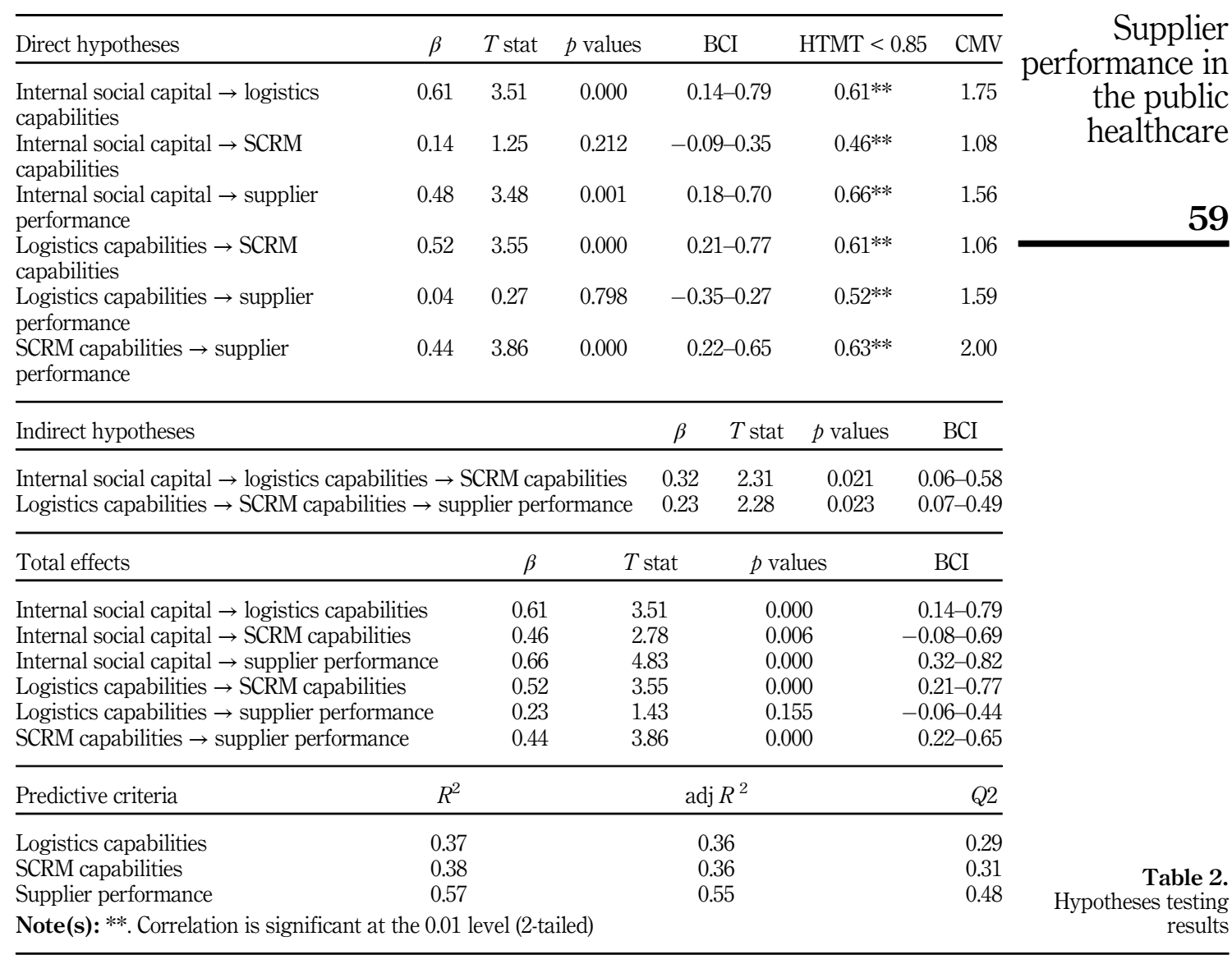

which enabled them to give unbiased responses. Further, we also contacted three professional academics and two managers to ensure the items are clear and captured their respective constructs. We further conducted Harman's single-factor test on all variables, by loading them to a principal component factor and using the unrotated solution. The principal component analysis of all the variables used in our model showed nine factors with eigenvalues greater than $1(77.739 \%)$ of the variance in the data. We identified more than one factor, whereby the first factor accounted for $31.643 \%$ of the variance, and the unrotated factor structure did not show a general factor. Then, we evaluated both the vertical and lateral inner values for variation inflation factor of the relationship in the partial least square structural equation model (PLS-SEM) as recommended by Kock and Hadaya (2018). In Table 2, the results show that all the inner VIF values for the vertical and lateral relationship were all below the threshold value of 3.3, indicating that common method bias is unlikely to affect our conclusions.

\section{Analysis of findings}

4.1 Descriptive results

The descriptive results indicated that majority of the health facilities studied belongs to the health centre II category. In Uganda, health facilities are categorised based on scope of 
JBSED 3,1 operation and range of services offered: hospitals operate at national, regional and district levels; health centre 1V operates at county/constituency level. Health centre III operates at sub-county level, while health centre II serves the parish level. This study focused on the lower categories because they are located in the rural areas and are more affected by logistics and supply chain challenges than those situated in urbanised areas, where physical infrastructure is fairly well-developed. The majority of health facilities have been in operation for more than 20 years, and employs between 5 and 49 workers, implying that it falls in the small enterprise category. Regarding the individual respondents' characteristics, most of them belong to 31-40 age categories, had a bachelor's degree and worked between 6 and 10 years. Furthermore, health facilities rated moderately on the study variables of logistics capabilities, internal social capital, SCRM capabilities and SP (Mean $=3.956$, SD $=0.523$ ), $($ Mean $=3.885, \mathrm{SD}=0.493),($ Mean $=3.639, \mathrm{SD}=0.621)$ and $($ Mean $=3.942, \mathrm{SD}=0.435)$. We also find that there were positive and significant associations between the study variables.

\subsection{Hypotheses tests}

Using bootstrapping with 10,000 sub-samples with no sign significant option at $95 \%$ bias corrected confidence interval, the results reveal that most of the hypothesised relationships are statistically significant $(\phi \leq 0.05)$. From the results presented in Table 2 and Figure 1 , we found positive and significant relationships between: internal social capital and supplier performance $\left(\beta=0.48, p=0.000, f^{2}=0.34\right.$, with lower and upper boundaries of the 95 th $\mathrm{BCa}$ CI values of 0.18 and 0.70$)$, internal social capital and logistics capabilities $(\beta=0.61, p=0.000$, $f^{2}=0.58$ with lower and upper boundaries of the 95th $\mathrm{BCa} C \mathrm{CI}$ values of 0.14 and 0.79 ), logistics capabilities and SCRM capabilities $\left(\beta=0.52, p=0.000, f^{2}=0.28\right.$, with lower and upper boundaries of the 95th BCa CI values of 0.21 and 0.77) and SCRM capabilities and supplier performance $\left(\beta=0.44, p=0.000, f^{2}=0.28\right.$, with lower and upper boundaries of the 95th BCa CI values of 0.22 and 0.65), substantiating H1, H2, H5 and H6. Further, we found a positive but non-significant relationship between internal social capital and SCRM capabilities $\left(\beta=0.14, p=0.212, f^{2}=-0.02\right.$, with lower and upper boundaries of the 95th $\mathrm{BCa}$ CI values of -0.09 and 0.35$)$, logistics capabilities and supplier performance $(\beta=0.04$, $p=0.798, f^{2}=0.00$, with lower and upper boundaries of the 95 th $\mathrm{BCa}$ CI values of -0.35 and 0.27 ), not supporting $\mathrm{H} 3$ and $\mathrm{H} 4$.

The $R^{2}$ values of $0.57,0.38$ and 0.37 for supplier performance, SCRM capabilities and logistics capabilities further support our model's in-sample model fit since any predictive variance above (0) shows predictive relevance (Hair et al., 2020). Finally, we ran a blindfolding procedure with an omission distance of seven to assess the predictive relevance of our model using cross-validated redundancy values $(Q 2)$ index. Results indicate a correct predictive relevance $(0.48,0.31$ and 0.29$)$ for supplier performance, SCRM capabilities and logistics capabilities, further supporting the model's predictive accuracy. The computation of PLSSEM paths coefficients linking the study constructs was based on a series of regression analysis, and we ascertained whether collinearity affects our regression results. Based on the results in Table 2, all inner VIF values were below the cut-off of 5 (Hair et al., 2020), confirming that collinearity is not a critical issue in our study findings.

\subsection{Mediation testing}

We assessed the mediating role of logistics capabilities in the relationship between internal social capital and SCRM capabilities as well as that of SCRM capabilities in the relationship between logistics capabilities and supplier performance simultaneously (Nitzl et al., 2016). The results in Table 2 show that logistics capabilities play a significant mediating role in the relationship between internal social capital and SCRM capabilities $(\beta=0.32, p=0.021$, with lower and upper boundaries of the 95th $\mathrm{BCa}$ CI values of 0.06 and 0.58 ). Also, SCRM 
capabilities mediate in the relationship between logistics capabilities and supplier performance $(\beta=0.23, p=0.023$, with lower and upper boundaries of the 95 th $\mathrm{BCa} \mathrm{CI}$ values of 0.07 and 0.49 ), confirming theorised (H7) and (H8). Conclusively, the findings reveal that logistics capabilities partially mediate between internal social capital and SCRM capabilities, while SCRM capabilities fully mediate between logistics capabilities and supplier performance $(\mathrm{VAF}=52.5 \%$ and $100 \%)$, respectively.
Supplier performance in the public healthcare

\section{Discussion}

With regards to the goal of establishing the relationship between internal social capital and supplier performance, in accordance with the first hypothesis (H1), the results indicated that there is a positive and significant relationship between internal social capital and supplier performance. This implies that internal relational, cognitive and structural capital elements influence SP in the healthcare facilities. These results are consistent with previous studies that emphasise the positive role of internal social capital components in enhancing supplier performance (Zsidisin et al., 2015; Alghababsheh and Gallear, 2020). Particularly, the findings suggest that health facilities that create several avenues for personal interactions among employees as well as embrace a family atmosphere, where employees feel concern and have mutual respect for each other achieve improved supplier performance. This is because such internal relational capital enhances trust among employees, facilitates communication and implementation of effective knowledge-sharing routines and governance mechanisms that offer direct benefits for the suppliers (Huang et al., 2014). Furthermore, health facilities that embrace internal cognitive capital by setting up clear goals, vision and missions to guide employees in ensuring collective performance and viewing each other as partners can achieve improved SP. This is supported by Tassabehji and Moorhouse (2008), who argued that internal politics in some organisations create a climate that does not facilitate supply management, thereby constraining SP. In addition, health facilities that develop clear structures that facilitate employees in easily accessing each other, sharing information and encouraging teamwork are able to achieve improved supplier performance.

The results of this study give support to the positive relationship of internal social capital on logistics capabilities in substantiation of H2. This implies that possession of cognitive, structural and relational capital within the health facilities can help to improve their information management and supply management capabilities. These findings concur with previous studies that support the role of social capital in building information management capabilities (Kemper et al., 2013; Polyviou et al., 2019). Hence, health facilities that for example have clear goals, mission and vision, encourage personal interactions among employees, embrace information sharing among employees and encourage teamwork are able to strengthen their logistics capabilities. This is further supported by Tassabehji and Moorhouse (2008), who argued that an organisational climate that is characterised by internal politics constrain the development of supply management capabilities. These findings are also in line with those of Zhao et al. (2011), which confirmed that internal social capital reflected in extensive cross-functional integration in the buying firm facilitates supplier involvement in effective problem solving and logistics planning.

In support of $\mathrm{H} 5$, the study found a positive and significant relationship between logistics capabilities and SCRM capabilities. This implies that health facilities with improved supply management and information management capabilities are able to build robustness and resilience in their upstream supply chains. Thus, health facilities that establish collaborative relationships with suppliers as well as synchronises their logistics operations to ensure integration with those of their supplier operations are able to be robust and resilient in the event of supply chain disruptions. This is in line with the previous studies (Gligor and Holcomb, 2012, 2014; Selvaraj and Wesley, 2020; Brix-Asala et al., 2021), which underlined 
JBSED 3,1

62

that logistics capabilities relating to demand management and information management are important in effective response to market volatility, supply chain uncertainties and risk. For example, information management capabilities can help to increase visibility and knowledge sharing about impending supply chain threats, which can enable health facilities to build appropriate resilience and robustness capabilities (Brandon-Jones et al., 2014).

Furthermore, the study revealed that there is a positive and significant relationship between SCRM capabilities and SP in support of H6. This implies for example that health facilities which are able to quickly recover from supply chain disruptions and spare sufficient time to consider most effective reactions to supply chain disruptions through contingence plans can ensure SP in the form of reduced user complaints, reduced lead-times and improved quality. These findings are in line with Zhang and Wang (2011), who stressed that building supply chain robustness is vital for ensuring supply chain performance. Similarly, Riley et al. (2016) revealed that warning and recovery SCRM capabilities are fundamental for enhancing performance. However, the study results did not yield support for $\mathrm{H} 3$ since the positive relationship between internal social capital and SCRM capabilities was non-significant. These findings contradict previous studies such as Gligor and Holcomb (2012), Polyviou et al. (2019) and Cui et al. (2020), which emphasise the positive role of social capital in building SCRM capabilities. This can be explained by the supportive results for $\mathrm{H} 7$ of the mediating role of logistics capabilities, whereby internal social capital does not directly influence SCRM capabilities but it can also be utilised in building logistics capabilities, which can then enhance supply chain resilience and robustness. Indeed recent research has shown that social capital can create more risks but can also be used to build logistics capabilities such as information exchange management capabilities, which can thereafter enhance SCRM capabilities (Alghababsheh and Gallear, 2020).

Finally, the direct path represented by $\mathrm{H} 4$ of the potential positive and significant relationship between logistics capabilities and SP was not supported. These findings are inconsistent with those of previous scholars (Chuah et al., 2010; Fugate et al., 2010; Day et al., 2015; Salam and Khan, 2018; Brix-Asala et al., 2021), who underline the role of logistics capabilities in enhancing supplier performance. However, this can be explained by the finding of a full mediating effect of SCRM capabilities between logistics capabilities and SP in support of H8. This suggests that the only way through which logistics capabilities can influence SP in this case is indirectly through building SCRM capabilities. This is in line with Brix-Asala et al. (2021), who established that logistics integration capabilities are important for managing supply chain risks, which consequently leads to better supplier performance.

\section{Conclusion}

This paper sought to examine the relationship between logistics capabilities, internal social capital, SCRM capabilities and SP in the Ugandan healthcare sector. Overall the results indicate that there are positive and significant relationships between the following pairs of variables: internal social capital and SP, internal social capital and logistics capabilities, logistics capabilities and SCRM capabilities, and SCRM capabilities and SP. However, the relationship between internal social capital and SCRM capabilities and that between logistics capabilities and supplier performance were found to be non-significant. Furthermore, the study confirmed the indirect influence of internal social capital on SCRM capabilities through logistics capabilities and that of logistics capabilities on SP through SCRM capabilities.

\subsection{Theoretical implications}

Through the RBV and related dynamic capabilities theoretical perspectives, this study contributes to the scholarly debate on the relationships between logistics capabilities, internal 
social capital, SCRM capabilities and supplier performance. Hence, we contribute to the research on the antecedents of supplier performance in the public health sector in a developing country, which has been limited. Moreover, the findings of this study did not support the positive significant relationship between internal social capital and SCRM capabilities and that between logistics capabilities and SP that were hitherto hypothesised. The establishment of an indirect effect of internal social capital on SCRM capabilities through logistics capabilities and that of logistics capabilities on SP through SCRM capabilities has contributed to the literature regarding the mechanism through which supplier performance can be enhanced, and this is expected to trigger more scholarly debate on the exact relationships between the variables examined in this paper.

\subsection{Implications for practice}

This study provides some recommendations for practice in order to improve SP performance in public health facilities. First, managers in the health facilities should create conditions necessary for the development of appropriate relational, cognitive and structural capital elements. Health facilities should embrace a family atmosphere where employees "feel at home" while at work, feel dedicated to perform their respective duties, become loyal and mutually respectful to each other. The management of health facilities should set up clear goals, vision and missions, which employees should be encouraged to pursue collectively. Employees should be encouraged to view each other as partners rather than indulging in internal politicking, which creates a climate that does not facilitate supply management. The management should also establish clear structures, encourage employee associations and interactions, ensure efficient communication and information sharing, espouse teamwork and narrow the interaction gap between managers and subordinates.

Second, managers in healthcare facilities should advise the government to allocate enough funding to provide resources necessary for building logistics capabilities. The government should ensure that health facilities have sufficient logistics information systems to facilitate information sharing internally within the health facilities and with key suppliers. Information and communication technology should be enhanced to capture and maintain real time data that be converted into knowledge necessary to facilitate performance improvement. Hence, managers should for example, ensure that their health facilities are equipped with sufficient data management services and architectures, reliable network communication services, enough servers, adequate processors and integrative systems like ERP as well as traceability technologies like RFID. Further, managers in the health facilities should ensure collaborative relationships with suppliers as well as synchronise their logistics operations to ensure that they are integrated with those of their key suppliers.

Third, managers of health facilities should ensure that their supply networks are resilient and robust. They should for example build and maintain a risk management section and create a risk management culture, whereby health facilities should anticipate and prepare for disruptions to minimise risk occurrence and also invest time in contingency planning to consider most effective reactions in case of risk events. Health facilities should also enhance their adaptive capacity necessary for resilience through allocating resources for supply chain process re-engineering, e.g. by employing multi-skilled labour force, maintaining prequalified suppliers or using multiple sourcing.

\subsection{Limitations and areas for further research}

The study has some limitations worth acknowledging as follows: first, this study used a cross-sectional quantitative survey design using a structured questionnaire to test research hypotheses derived from the literature. This limited the ability to get in-depth information regarding how and why the findings appeared the way they did. A qualitative case-based 
JBSED 3,1 study using in-depth interviews is important to offer in-depth understanding of the study phenomena. Second, this research was done in public healthcare facilities in rural districts of Uganda, and this may not represent the entire Ugandan health facilities as well as the entire healthcare industry in developing countries. Similar research can be conducted in all Ugandan healthcare facilities and in other developing countries to improve on the external validity of findings.

\section{References}

Ahimbisibwe, A., Muhwezi, M. and Nangoli, S. (2012), "Outsourced contracts, buyer-supplier trust, supplier opportunistic behavior and supplier performance in Ugandan public procuring and disposing entities", Journal of Public Procurement, Vol. 12 No. 4, pp. 435-470.

Ahmed, W. and Huma, S. (2021), "Impact of lean and agile strategies on supply chain risk management", Total Quality Management and Business Excellence, Vol. 32 Nos 1-2, pp. 33-56, doi: 10.1080/14783363.2018.1529558.

Alghababsheh, M. and Gallear, D. (2020), "Social capital in buyer-supplier relationships: a review of antecedents, benefits, risks, and boundary conditions", Industrial Marketing Management, Vol. 91, pp. 338-361.

Bhardwaj, A. and Ketokivi, M. (2021), "Bilateral dependency and supplier performance ambiguity in supply chain contracting: evidence from the railroad industry", Journal of Operations Management, Vol. 67 No. 1, pp. 49-70, doi: 10.1002/joom.1103.

BMAU report (2017), Budget Monitoring and Accountability Unit, Ministry of Finance, Planning and Economic Development.

Brandon-Jones, E., Squire, B., Autry, C. and Petersen, K. (2014), "A contingent resource-based perspective of supply chain resilience and robustness", Journal of Supply Chain Management, Vol. 50 No. 3, pp. 55-73.

Brix-Asala, C., Seuring, S., Sauer, P., Zehendner, A. and Schilling, L. (2021), "Resolving the base of the pyramid inclusion paradox through supplier development", Business Strategy and the Environment. doi: 10.1002/bse.2798.

Cai, S., Jun, M. and Yang, Z. (2010), "Implementing supply chain information integration in China: the role of institutional forces and trust", Journal of Operations Management, Vol. 28, pp. 257-268.

Carlos, M.J. (2011), "Social capital and dynamic capabilities in international performance of SMEs", Journal of Strategy and Management, Vol. 4 No. 4, pp. 404-421.

Chen, Y. and Chen, J. (2019), "Mediated power and sustainable supplier management (SSM) Linking power use, justice, and supplier performance", International Journal of Physical Distribution and Logistics Management, Vol. 49 No. 8, pp. 861-878.

Cheung, Y., Haw, I., Hu, B., Swink, M. and Zhang, W. (2020), "Common institutional investors and supplier performance in supply chains", Journal of Operations Management, Vol. 66 No. 6, pp. $670-696$, doi: 10.1002/joom.1089.

Chuah, P., Wong, W., Ramayah, T. and Jantan, M. (2010), "Organizational context, supplier management practices and supplier performance: a case study of a multinational company in Malaysia”, Journal of Enterprise Information Management, Vol. 23 No. 6, pp. 724-758.

Cousins, P.D., Handfield, R.B., Lawson, B. and Petersen, K.J. (2006), "Creating supply chain relational capital: the impact of formal and informal socialization processes", Journal of Operations Management, Vol. 24 No. 6, pp. 851-863.

Cui, G., Jin, C. and Lee, J. (2020), "How risk managers' psychological and social capital promotes the development of risk-management capabilities", Sustainability, Vol. 12 No. 11, p. 4666.

Day, M., Lichtenstein, S. and Samouel, P. (2015), "Supply management capabilities, routine bundles and their impact on firm performance", International Journal of Production Economics, Vol. 164, pp. 1-13. 
Dyer, J. and Singh, H. (1998), "The relational view: cooperative strategy and sources of interorganizational competitive advantage", Academy of Management Review, Vol. 23 No. 4, pp. 660-679.

Esper, T.L., Fugate, B.S. and Davis-Sramek, B. (2007), "Logistics learning capability: sustaining the competitive advantage gained through logistics leverage", Journal of Business Logistics, Vol. 28 No. 2, pp. $57-81$.

Field, J. and Meile, C. (2008), "Supplier relations and supply chain performance in financial services processes", International Journal of Operations and Production Management, Vol. 28 No. 2, pp. 185-206.

Fugate, B.S., Mentzer, J.T. and Stank, T.P. (2010), "Logistics performance: efficiency, effectiveness, and differentiation”, Journal of Business Logistics, Vol. 31 No. 1, pp. 43-62.

Gao, S., Sung, M. and Zhang, J. (2013), "Risk management capability building in SMEs: a social capital perspective", International Small Business Journal, Vol. 31 No. 6, pp. 677-700.

Gligor, D. and Holcomb, M. (2012), "Understanding the role of logistics capabilities in achieving supply chain agility: a systematic literature review", Supply Chain Management: An International Journal, Vol. 17 No. 4, pp. 438-453.

Gligor, D. and Holcomb, M. (2014), "The road to supply chain agility: an RBV perspective on the role of logistics capabilities", The International Journal of Logistics Management, Vol. 25 No. 1, pp. 160-179.

Gölgeci, I. and Kuivalainen, O. (2020), "Does social capital matter for supply chain resilience? The role of absorptive capacity and marketing-supply chain management alignment", Industrial Marketing Management, Vol. 84, pp. 63-74.

HairJr, J., Howarda, M. and Nitzl, C. (2020), "Assessing measurement model quality in PLS-SEM using confirmatory composite analysis”, Journal of Business Research, Vol. 109, pp. 101-110.

Henseler, J., Ringle, C.M. and Sarstedt, M. (2015), “A new criterion for assessing discriminant validity in variance-based structural equation modelling", Journal of the Academy of Marketing Science, Vol. 43 No. 1, pp. 1-21.

Huang, M., Yen, G. and Liu, T. (2014), "Reexamining supply chain integration and the supplier's performance relationships under uncertainty", Supply Chain Management: An International Journal, Vol. 19 No. 1, pp. 64-78.

Jahre, M., Dumoulin, L., Greenhalgh, L., Hudspeth, C., Limlim, P. and Spindler, A. (2012), "Improving health in developing countries: reducing complexity of drug supply chains", Journal of Humanitarian Logistics and Supply Chain Management, Vol. 2 No. 1, pp. 54-84.

Johnson, N., Elliott, D. and Drake, P. (2013), "Exploring the role of social capital in facilitating supply chain resilience", Supply Chain Management: An International Journal, Vol. 18 No. 3, pp. 324-336.

Joong-Kun, C., John, O. and Harry, S. (2008), "Logistics capability, logistics outsourcing and firm performance in an e-commerce market", International Journal of Physical Distribution and Logistics Management, Vol. 38 No. 5, pp. 336-359.

Kemper, J., Schilke, O. and Brettel, M. (2013), "Social capital as a microlevel origin of organizational capabilities", Journal of Production Innovation Management, Vol. 30 No. 3, pp. 589-603.

Kim, K., Lee, J. and Lee, S. (2017), “The effects of supply chain fairness and the buyer's power sources on the innovation performance of the supplier: a mediating role of social capital accumulation", Journal of Business and Industrial Marketing, Vol. 32 No. 7, pp. 987-997.

Kock, N. and Hadaya, P. (2018), "Minimum sample size estimation in PLS-SEM: the inverse square root and gamma-exponential methods", Information Systems Journal, Vol. 28 No. 1, pp. 227-261.

Kraaijenbrink, J., Spender, J. and Groen, J. (2010), “The resource-based view: a review and assessment of its critiques", Journal of Management, Vol. 36 No. 1, pp. 349-372. 
JBSED

3,1

66

Kwak, D., Seo, Y. and Mason, R. (2018), "Investigating the relationship between supply chain innovation, risk management capabilities and competitive advantage in global supply chains", International Journal of Operations and Production Management, Vol. 38 No. 1, pp. 211-229.

Lee, A., Chan, F. and PuI, X. (2018), "Impact of supplier development on supplier's performance", Industrial Management and Data Systems, Vol. 118 No. 6, pp. 1192-1208.

Li, Y., Ye, F. and Sheu, C. (2014), "Social capital, information sharing and performance evidence from China", International Journal of Operations and Production Management, Vol. 34 No. 11, pp. 1440-1462.

Mandal, S., Korasiga, V., Bhattacharya, S. and Dastidar, S. (2016), "Achieving supply chain resilience. The contribution of logistics and supply chain capabilities", International Journal of Disaster Resilience in the Built Environment, Vol. 7 No. 5, pp. 544-562.

Mentzer, J.T., Min, S. and Bobbitt, L.M. (2004), "Toward a unified theory of logistics", International Journal of Physical Distribution and Logistics Management, Vol. 34 No. 8, pp. 606-627.

Morash, E.A., Droge, C.L.M. and Vickery, S.K. (1996), "Strategic logistics capabilities for competitive advantage and firm success", Journal of Business Logistics, Vol. 17 No. 1, pp. 1-22.

Mwesiumo, D., Nujen, B. and Buvik, A. (2021), "Driving collaborative supply risk mitigation in buyersupplier relationships", Supply Chain Forum: An International Journal. doi: 10.1080/16258312. 2021.1932567.

Nahapiet, J. and Ghoshal, S. (1998), "Social capital, intellectual capital, and the organizational advantage", Academy of Management Review, Vol. 23 No. 2, pp. 242-266.

Narasimhan, R., Mahapatra, S. and Arlbjørn, S. (2008), "Impact of relational norms, supplier development and trust on supplier performance", Operations Management Research, Vol. 1, pp. 24-30.

Nitzl, C., Roldan, J.L. and Cepeda, G. (2016), "Mediation analysis in partial least squares path modeling", Industrial Management and Data Systems, Vol. 116 No. 9, pp. 1849-1864.

Ntayi, J., Namugenyi, I. and Eyaa, S. (2010), "Supplier delivery performance in Ugandan public procurement contracts", Journal of Public Procurement, Vol. 10 No. 4, pp. 479-511.

Ojha, D., Shockley, J., Rogers, P., Cooper, D. and Patel, P. (2019), "Managing supplier flexibility performance as a relational exchange investment in make-to-stock versus make-to-order production environments", Journal of Business and Industrial Marketing. doi: 10.1108/JBIM-052019-0200.

Paparoidamis, N., Katsikeas, C. and Chumpitaz, R. (2019), "The role of supplier performance in building customer trust and loyalty: a cross-country examination", Industrial Marketing Management, Vol. 78, pp. 183-197, doi: 10.1016/j.indmarman.2017.02.005.

Pinho, C. (2011), "Social capital and dynamic capabilities in international performance of SMEs", Journal of Strategy and Management, Vol. 4 No. 4, pp. 404-421.

Podsakoff, M., MacKenzie, B., Lee, J. and Podsakoff, N. (2003), "Common method biases in behavioral research: a critical review of the literature and recommended remedies", Journal of Applied Psychology, Vol. 88 No. 5, pp. 879-903.

Polyviou, M., Croxton, K. and Knemeyer, M. (2019), "Resilience of medium-sized firms to supply chain disruptions: the role of internal social capital", International Journal of Operations and Production Management, Vol. 40 No. 1, pp. 68-91, doi: 10.1108/IJOPM-09-2017-0530.

Ponomarov, S. and Holcomb, M. (2009), "Understanding the concept of supply chain resilience", The International Journal of Logistics Management, Vol. 20 No. 1, pp. 124-143.

Prahinski, C. and Benton, C. (2004), "Supplier evaluations: communication strategies to improve supplier performance", Journal of Operations Management, Vol. 22, pp. 39-62.

Rai, A., Pavlou, A., Ghiyoun, I. and Steve, D. (2012), "Interfirm it capability profiles and communications for cocreating relational value: evidence from the logistics industry", $M I S$ Quarterly, Vol. 36 No. 1, pp. 233-262. 
Riley, J.M., Klein, K., Miller, J. and Sridharan, V. (2016), "How internal integration, information sharing, and training affect supply chain risk management capabilities", International Journal of Physical Distribution and Logistics Management, Vol. 46 No. 10, pp. 953-980.

Rodrigues, S., Potter, A., Naim, M. and Whiteing, A. (2008), "Establishing a transport operation focused uncertainty model for the supply chain", International Journal of Physical Distribution and Logistics Management, Vol. 38 No. 5, pp. 388-411.

Salam, M. and Khan, S. (2018), "Achieving supply chain excellence through supplier management: a case study of fast moving consumer goods", Benchmarking: An International Journal, Vol. 25 No. 9, pp. 4084-4102, doi: 10.1108/BIJ-02-2018-0042.

Scott, G., Autry, C. and Daugherty, P. (2014), "Organizational implants and logistics service innovation: a relational social capital perspective”, Transportation Journal, Vol. 53 No. 2, pp. 180-210.

Selvaraj, J. and Wesley, R. (2020), "Integrated supply chain risk management capabilities and its impact on supply chain demand management - an empirical study", International Journal of Business Information Systems, Vol. 34 No. 3, doi: 10.1504/IJBIS.2020.108691.

Tassabehji, R. and Moorhouse, A. (2008), "The changing role of procurement: developing professional effectiveness", Journal of Purchasing and Supply Management, Vol. 14 No. 1, pp. 55-68.

Teece, D.J., Pisano, G.P. and Shuen, A. (1997), "Dynamic capabilities and strategic management", Strategic Management Journal, Vol. 18, pp. 509-533.

Tukamuhabwa, B.R., Stevenson, M., Busby, J. and Zorzini, M. (2015), "Supply chain resilience: definition, review and theoretical foundations for further study", International Journal of Production Research, Vol. 53 No. 18, pp. 5592-5623.

Vlachos, I. (2020), "Contract design and supplier performance: an empirical investigation using multicriteria, decision analysis", International Journal of Productivity and Performance Management. doi: 10.1108/IJPPM-10-2019-0492.

Wagner, S. and Bode, C. (2008), "An empirical examination of supply chain performance along several dimensions of risk", Journal of Business Logistics, Vol. 29 No. 1, pp. 307-325.

Wang, M., Jie, F. and Abareshi, A. (2018), "Logistics capability, supply chain uncertainty and risk, and logistics performance: an empirical analysis of Australian courier industry", Operations and Supply Chain Management, Vol. 11 No. 1, pp. 45-54.

Whipple, J.M., Wiedmer, R. and Boyer, K.K. (2015), "A dyadic investigation of collaborative competence, social capital, and performance in buyer-supplier relationships", Journal of Supply Chain Management, Vol. 51 No. 2, pp. 3-21.

Wieland, A. and Wallenburg, C. (2013), "The influence of relational competencies on supply chain resilience: a relational view", International Journal of Physical Distribution and Logistics Management, Vol. 43 No. 4, pp. 300-320.

Wiengarten, F., Pagell, M., Ahmed, U. and Gimenez, C. (2014), "Do a country's logistical capabilities moderate the external integration performance relationship?", Journal of Operations Management, Vol. 32 Nos 1-2, pp. 51-63.

Yang, J., Xie, H., Yu, G. and Liu, M. (2021), “Antecedents and consequences of supply chain risk management capabilities: an investigation in the post-coronavirus crisis", International Journal of Production Research, Vol. 59 No. 5, pp. 1573-1585.

Zelbst, P.J., Green, J.K.W., Sower, V.E. and Baker, G. (2010), "RFID utilization and information sharing: the impact on supply chain performance", Journal of Business and Industrial Marketing, Vol. 25 No. 8, pp. 582-589.

Zhang, X. and Wang, H. (2011), "Empirical research on associations among information technology, supply chain robustness and supply chain performance", International Journal of Business and Management, Vol. 6 No. 2, pp. 231-135. 
JBSED 3,1

68
Zhao, X., Huo, B., Selen, W. and Yeung, Y. (2011), "The impact of relationship commitment and internal integration on external integration", Journal of Operations Management, Vol. 29 Nos 1-2, pp. 17-32.

Zhao, L., Huo, B., Sun, L. and Zhao, X. (2013), "The impact of supply chain risk on supply chain integration and company performance: a global investigation”, Supply Chain Management: An International Journal, Vol. 18 No. 2, pp. 115-131.

Zsidisin, G., Hartley, J., Bernardes, E. and Saunders, L. (2015), "Examining supply market scanning and internal communication climate as facilitators of supply chain integration", Supply Chain Management: An International Journal, Vol. 20 No. 5, pp. 549-560.

\section{Further reading}

Field, A. (2009), Discovering Statistics Using SPSS, (3. baskı), Sage Publications, New York, NY.

\section{Corresponding author}

Benjamin Tukamuhabwa can be contacted at: btukamuhabwa@mubs.ac.ug

For instructions on how to order reprints of this article, please visit our website: 